\title{
Pain Relief Following Shoulder Arthroscopy In Patients Receiving Preoperative Stellate Ganglion Block - Some More Facts !
}

\section{TO THE EDITOR:}

We read with great interest the article "Effects of Ultrasound-Guided Stellate Ganglion Block on Acute Pain after Arthroscopic Shoulder Surgery" by Choi et al (1). The authors need to be congratulated for their original research work. However, the authors' conclusion regarding ineffectiveness of stellate ganglion block (SGB) in controlling postoperative acute pain in arthroscopic shoulder surgery invites further discussion. We wish to highlight and share a few relevant issues pertaining to the role of preoperative SGB from our experience (2) as well as from a published study (1). First, in our study, SGB significantly reduced the visual analog scale (VAS) at rest as compared to the dynamic pain of movement at 4 and 6 hours postoperatively. This also was reflected in significant postoperative tramadol sparing up to 24 hours in our study (2). Though the VAS on movement was also lower in the lignocaine group as compared to the control group, it failed to reach statistical significance (2). It would be appropriate if Choi et al also mentioned the nature of pain measured postoperatively; rest pain or pain on movement (1). This has clinical implications as acute pain relief at rest provides comfort to patients in bed while pain relief on movement is beneficial in preventing cardiopulmonary and thromboembolic complications (3). The proposed mechanism for rest pain relief in the operated arm in the lignocaine group had been ascribed to SGBinduced vasodilation and washing out of inflammatory mediators, resulting in modulation and attenuation of sympathetic component of $A \delta$ and C- fibers in deeper muscles (4-6). The insignificant difference exhibited by VAS on movement had been attributed to the presence of more than one mechanism of pain during movements and all of which were unable to be controlled by SGB alone $(7,8)$. The study by Choi et al would have assumed more relevance if this aspect of VAS measurement would also have been considered in providing more implications to the study (1).

Secondly, the authors' claim of using SGB as monotherapy has attenuated significance when multiple co-analgesics like fentanyl, ketorolac, and tramadol were used simultaneously. Postoperative pain relief in shoulder arthroscopy with polypharmacy could have reduced VAS, which itself has lesser potential in generating nociceptive inputs. A possibility of observer bias could not be ruled out due to the absence of temperature monitoring in the control group (1).

Thirdly, the vasoconstrictive effects of adrenaline used in the irrigation fluid for maintenance of hemostasis had the potential to negate the very postulated vasodilatory mechanism of SGB in promoting analgesia (7). Though the effects of epinephrine, absorbed systematically or locally, on SGB are somewhat unknown, (1) sympathomimetics like noradrenaline have been known to exacerbate pain in damaged or burned tissue, an effect reduced by sympathetic blockade (8). In an earlier RCT (2) and a case report (9) where adrenaline had not been used in the blocked and operated arm, preoperative SGB had provided analgesic sparing. As described earlier, vasoconstrictive effects of epinephrine-mixed irrigation fluids in shoulder arthroscopy (1) possibly prevented the washout of inflammatory mediators in the surgical arm and enhanced sensitization of functional and dormant nociceptors (10), leading to a similar VAS in both groups (1).

Lastly, we would like to comment on the implications of nurse-based postoperative analgesia provided by Choi et al, that has become less popular these days while patient-controlled analgesia has become the standard of care (1). The current postoperative pain relief supports greater satisfactory results with patientcontrolled analgesia (11). Provision of nurse-based postoperative analgesia has passive involvement of patient, rather than active, involvement. This probably would have influenced the true representation of pain VAS scoring in these patients (1).

In the light of above observations the conclusion drawn by Choi et al (1) needs cautious interpretation before reaching to any inference. Further studies would definitely throw more light on the issue.

Dr. Deepak Thapa

Associate Professor

Department of Anaesthesia and Intensive Care

Government Medical College and Hospital 
Sector 32, Chandigarh, India

E mail: dpkthapa@gmail.com

Vanita Ahuja, MD

Assistant Professor

Department of Anaesthesia and Intensive Care

Government Medical College and Hospital

sector 32 Chandigarh

India

E-mail: vanitaanupam@yahoo.co.in
Prof Satinder Gomabar

Prof and Head

Department of Anaesthesia and Intensive Care Government Medical College and Hospital

sector 32 Chandigarh, India

E mail: drsgombar57@gmail.com

\section{Reference}

1. Choi EM, Kim EM, Chung MH, Park JH, Lee HK, Choi YR, Lee M. Effects of ultrasound-guided stellate ganglion block on acute pain after arthroscopic shoulder surgery. Pain Physician 2015; 18: E379$\mathrm{E}_{3} 88$

2. Kumar N, Thapa D, Gombar S, Ahuja V, Gupta R. Analgesic efficacy of pre-operative stellate ganglion block on postoperative pain relief: A randomised controlled trial. Anaesthesia 2014; 69:954660.

3. Breivik $H$, Borchgrevink PC, Allen SM, Rosseland LA, Romundstad L, Hals EK, Kvarstein G, Stubhaug A. Assessment of pain. Br J Anaesth 2008; 101:17-24.

4. Singelyn FJ, Lhotel L, Fabre B. Pain re- lief after arthroscopic shoulder surgery: A comparison of intraarticular analgesia, suprascapular nerve block, and interscalene brachial plexus block. Anesth Analg 2004; 99:589-592.

5. Ossipov MH, Dussor GO, Porreca F. Central modulation of pain. J Clin Invest 2010; 120:3779-3787.

6. W Jänig. The sympathetic nervous system in pain. Eur J Anaesthesiol Suppl 1995; 12:53-6o.

7. Jensen KH, Werther K, Stryger V, Schultz K, Falkenberg B. Arthroscopic shoulder surgery with epinephrine saline irrigation. Arthroscopy 2001; 17:578-581.

8. Holthusen $\mathrm{H}$, Stanton-Hicks $M$, Arndt JO. Sympathetic block does not reduce acute vascular pain in humans. Anesth Analg 1998; 86:588-590.

9. McDonnell JG, Finnerty O, Laffey JG. Stellate ganglion blockade for analgesia following upper limb surgery. Anaesthesia 2011; 66:611-614.

10. Kieschke J, Mense S, Prabhakar NR. Influence of adrenaline and hypoxia on rat muscle receptors in vitro. Prog Brain Res 1988; 74:91-97.

11. McNicol ED, Ferguson MC, Hudcova J. Patient controlled opioid analgesia versus non-patient controlled opioid analgesia for postoperative pain. Cochrane Database of Systematic Reviews 2015, Issue 6. Art. No.: CDoo3348. DOI:10.1002/14651858.CDo03348.pub3. 